\title{
Chitinases as Antibacterial Proteins: A Systematic Review
}

\author{
Suelen Carneiro de Medeiros ${ }^{1 *}$, José Edvar Monteiro-Júnior² ${ }^{2}$ Gleilton Weyne Passos Sales ${ }^{1}$, Thalles Barbosa Grangeiro² and Nádia Accioly \\ Pinto Nogueira ${ }^{1}$ \\ 'Departamento de Análises Clínicas e Toxicológicas, Centro de Ciências da Saúde, Universidade Federal do Ceará, Fortaleza, Ceará, BRAZIL. \\ 2Departamento de Biologia, Centro de Ciências, Universidade Federal do Ceará, Fortaleza, Ceará, BRAZIL.
}

\begin{abstract}
Chitinases are hydrolases that catalyze the cleavage of the $\beta-1,4-0$ glycosidic linkages in chitin, a polysaccharide abundantly found in nature. Chitin is an important structural component of the cell wall of most fungi and the exoskeleton of arthropods, including insects and crustaceans. These enzymes are widespread in the living world, being found in organisms from all three domains of life. Due to their hydrolytic activity on chitin, chitinases have great biotechnological potential in different areas, such as human health, agriculture and food technology. The antifungal, insecticidal and nematicidal effects of many chitinases have been intensively investigated in the scientific literature, aiming to exploit these properties to protect crops against phytopathogenic fungi and insect pests and parasitic nematodes. On the other hand, the effects of chitinases on bacteria have been underexploited, possibly because chitin is not present in bacterial cell walls. The aim of this study was to search the scientific literature for works describing chitinases with antibacterial activity. Three bibliographic databases were searched using the keywords "chitinase" and "antibacterial" as descriptors and the chosen articles were selected according to specific
\end{abstract}

inclusion and exclusion criteria. As a result, we identified only 5 reports wherein 6 purified chitinases have been shown experimentally to have antibacterial activity. Three out of these 6 antibacterial chitinases were shown to be bifunctional enzymes, which have chitinase and lysozyme activity. The possible mechanism of action of these antibacterial chitinases is discussed, highlighting their potential as antibacterial agents.

Key words: Antimicrobial, Chitin, Lysozyme, Peptidoglycan, Hydrolases.

Correspondence

Suelen Carneiro de Medeiros, Departamento de Análises Clínicas e Toxicológicas, Universidade Federal do Ceará, Rua Capitão Francisco Pedro, Rodolfo Teófilo, Fortaleza, Ceará, BRAZIL.

Phone: +55853366826

Email: sumedeiros86@gmail.com

DOI: $10.5530 / j y p .2018 .10 .33$

\section{INTRODUCTION}

Chitin is a linear and water-insoluble polysaccharide constituted by $N$-acetyl- $\beta$-D-glucosamine (GlcNAc) units linked through $\beta$-1,4 linkages. This polymer is the most abundant amino polysaccharide in nature and after cellulose, is the second most plentiful biopolymer on earth. It is an important structural component of the cell wall of many fungi and the exoskeleton of arthropods, such as insects and crustaceans, like crabs, shrimps and lobsters. Chitin is also found in the shell and radula of mollusks and the cuticle and egg shell of nematodes. ${ }^{1}$ Recently, Tang and co-workers have obtained evidences that chitin is endogenously produced in non-mammalian vertebrates, including fishes and amphibians. ${ }^{2}$

Chitinases (EC 3.2.1.14) are glycoside hydrolases (GHs) that catalyze the cleavage of the $\beta-1,4$ glysosidic bonds between the GlcNAc residues that form the chitin chains. Based on the similarities of their amino acid sequences, most chitinases are grouped into the GH18 and GH19 families according to the current classification of the Carbohydrate-Active Enzymes (CAZy; http://www.cazy.org) database. ${ }^{3,4}$ Chitinases are found in a wide range of organisms including humans, seed plants, insects, bacteria and fungi. These enzymes are involved in a variety of biological processes, such as the remodeling of chitin in the cell walls of fungi and the exoskeleton of arthropods during the periods of growth and development, ${ }^{5}$ the utilization of chitin as a source of carbon and nitrogen by many bacteria ${ }^{6}$ and participation in defense mechanisms against pathogens. ${ }^{7}$ In plants, for example, besides being expressed in different tissues and organs during the regular growth and development, some chitinases act as pathogenesis-related proteins, whose expression is upregulated in response to chitin-containing pathogens. The hydrolytic action of these induced chitinases on the chitin fibers of the pathogen's cell wall impairs its growth and spread, whereas the chitin oligomers released are recognized by plant chitin receptors, which trigger other defense reactions. ${ }^{8}$ In carnivorous plants, some chitinases also play a digestive role, being used along with other hydrolytic enzymes to digest caught prey in their pitchers. ${ }^{9}$

The great interest in the study of chitinases primarily relies on their enzymatic action on chitin. Endo-chitinases, for example, randomly cleave chitin chains at internal sites, producing low molecular mass chito-oligomers with 2 to $6 \mathrm{GlcNAc}$ units, whereas exo-chitinases catalyze the progressive release of $N, N^{\prime}$-diacetylchitobiose $\left[(\mathrm{GlcNAc})_{2}\right]$ or $N, N^{\prime}, N^{\prime \prime}$-triacetylchitotriose $\left[(\mathrm{GlcNAc})_{3}\right]$ from the chitin chains. ${ }^{10}$ Some exo-type chitinases attack the chitin chains at the non-reducing end, but others cleave the polymer at the opposite end. ${ }^{11}$ Due to their ability to degrade chitin, many chitinases can cause damages to the cell walls of fungi and cuticles of insects. The antifungal and insecticidal activities of these enzymes have attracted the attention of the biotechnologists, which has led to the development of transgenic crops with enhanced resistance to fungal pathogens and insect pests. ${ }^{12}$ Chitinases with toxic effects towards plant-parasitic nematodes have also been investigated as an alternative strategy to protect crops from the serious damages these organisms cause in many parts of the world. ${ }^{13}$ The nematicidal effect of chitinases is also due to their degradative activity on chitin chains, which causes destruction of the nematode's cuticle, intestine and egg shell. ${ }^{14}$ Furthermore, it is also well documented that $N$-acetyl-chitooligosaccharides, which can be obtained from chitin by treatment with chitinases, have antibacterial, antifungal, metastasis suppression and other biological 
activities, thus showing great biotechnological potential in areas as diverse as food technology, human health and agriculture. ${ }^{15}$

The aim of this study was to search the scientific literature for works describing chitinases with antibacterial activity and summarize their main findings, discussing the probable mechanisms responsible for the antibacterial activity of these proteins and their potential applications.

\section{MATERIALS AND METHODS}

Searches were performed on the following bibliographic databases: PubMed (http://www.ncbi.nlm.nih.gov/pubmed/), Web of Science (https://apps.webofknowledge.com/) and Scopus (http://www.scopus. com). Full-text articles, published until November 2017 and containing the words "chitinases" and "antibacterial" in their titles or abstracts were selected for further analysis. The appropriate papers were selected based on 2 criteria: (a) the reported antibacterial tests were performed using pure protein samples, as evidenced by denaturing gel electrophoresis, for example; and (b) the tested protein was a genuine chitinase, able to degrade chitin or chitin derivatives, as demonstrated by experimental data.

\section{RESULTS}

By searching the scientific literature, we have identified only 5 works that reported the purification and partial characterization of chitinases with antibacterial activity (Table 1). These chitinases included 3 proteins from bacterial species, ChiS from Bacillus pumilus SG2 ${ }^{16}$ and FI and FII from Pseudomonas aeruginosa K-187, ${ }^{17} 2$ proteins from fungi species, Aspergillus terreus ${ }^{18}$ and Monascus purpureus CCRC31499, ${ }^{19}$ and one protein (CpCHI) from papaya (Carica papaya). ${ }^{20}$ In most of these papers (4 out of 5), the antibacterial activity of the protein was determined using the agar disk-diffusion method, whereas in one of them, ${ }^{20}$ the authors used a dilution method. The chitinases FI and FII from $P$. aeruginosa K-187 showed a large spectrum of antibacterial effect, being able to inhibit the growth of different Gram-positive and Gram-negative species. ${ }^{17}$ In all these works, the chitinolytic nature of the purified proteins was demonstrated using enzymatic assays, in which their ability to degrade either colloidal chitin or glycol chitin was verified. For ChiS and $\mathrm{CpCHI}$, the authors also reported the amino acid sequences of the studied proteins, as deduced from their DNA coding sequences, which confirmed their identities as chitinases, belonging to the GH18 (ChiS) and GH19 (CpCHI) families. Three (ChiS, FI and FII) out of these 6 antibacterial chitinases had lysozyme activity, which was measured by the ability of the tested proteins to cause bacterial cell lysis, as evidenced by the decrease in optical density of a cell suspension of the target microorganism exposed to the enzyme. The $M$. purpureus chitinase did not show lysozyme activity, when tested towards a cell suspension of Micrococcus lysodeikticus, whereas for $\mathrm{CpCHI}$ and the chitinase from A. terreus, this biochemical activity was not investigated.

Besides the reports listed above, Wang and co-workers ${ }^{21}$ described the purification of Hypotin, a protein from peanut (Arachis hypogaea) seeds which showed antifungal activity towards a variety of fungi species as well as antibacterial activity towards Staphylococcus aureus. The classification of Hypotin as a chitinase was based on the similarity of its $\mathrm{N}$-terminal amino acid sequence with already known plant chitinases. However, those authors did not show any experimental evidence on the ability of Hypotin to degrade chitin or chitin derivatives, and their work was not included in our analysis.

It is noteworthy to mention that we also identified one paper that described the purification of a 55-amino acid residues peptide from the marine mussel Mytilus coruscus, which was named mytichitin-CB, that showed antifungal as well as antibacterial activity towards Gram-positive species. $^{22}$ Cloning of the cDNA encoding mytichitin-CB revealed that mytichitin-CB is derived from the processing of a chitotriosidase/ chitinase precursor with 446 amino acid residues. Nevertheless, no antibacterial activity of the chitotriosidase/chitinase itself was demonstrated, and this work was not included in the present analysis.

\section{DISCUSSION}

Very few works have reported the characterization of chitinases with antibacterial activity (Table 1), contrary to their antifungal activity, which has been documented since 1980 s. $^{23}$ Unlike fungi, bacteria cell walls do not contain chitin. Although genes encoding chitin synthase (CHS; EC 2.4.1.16), which catalyzes the elongation of chitin, have been recently discovered in some bacterial genomes ${ }^{24}$ species containing $\mathrm{CHS}$ genes represent only $0.9 \%$ of the 1218 bacterial genomes analyzed and to date there is no experimental evidence that chitin occurs in these few species. This is probably the main reason why many researchers have neglected bacterial species as possible targets for the action of chitinases. However, it has been shown that some chitinases from diverse sources, besides being able to cleave the $\mathrm{O}$-glycosidic bonds in chitin chains, also have lysozyme activity. ${ }^{25,26,27}$ Hevamine, a GH18 chitinase firstly purified from the latex of Hevea brasiliensis, is probably the better known chitinase with lysozyme activity. ${ }^{28,29}$

Most bacterial cells are encased by a cell wall constituted mainly by a mesh-like layer of peptidoglycan (PG), also known as murein, which guarantees cell integrity and shape. PG macromolecule is constituted by glycan chains cross-linked by short peptides. These glycan chains are composed of alternating residues of GlcNAc and $N$-acetylmuramic acid (MurNAc) linked by $\beta-1,4$ bonds. ${ }^{30,31}$ MurNAc is the ether of lactic acid and GlcNAc, in which a D-lactate residue is attached to the C-3 atom of the glucopyranoside ring. Indeed, the first step during PG biosynthesis is the conversion of UDP-GlcNAc to UDP-MurNAc. ${ }^{32}$

Lysozymes (muramidases) (EC 3.2.1.17), are glycoside hydrolases that cleave the $\beta-1,4$ linkages in murein, causing bacterial cell lysis, as first observed by Alexander Fleming. ${ }^{33}$ Besides their direct bacteriolytic action, these proteins also have an immunomodulatory function in the host's response to infection. ${ }^{34}$

Three (ChiS, FI and FII) out of the 6 antibacterial chitinases listed in Table 1 showed lysozyme activity which could be related to their bactericidal properties. ChiS is a GH18 enzyme, like hevamine, but the amino acid sequences of FI and FII were not reported, and the GH families to which they belong are not known. GH18 members adopt a conserved $(\beta / \alpha)_{8}$-barrel fold that do not share similarity with the lyzosyme-type fold. Furthermore, the cleavage specificities of hevamine and lysozymes for PG are distinct: hevamine hydrolyzes the linkage between the C-1 of GlcNAc and the C-4 of MurNAc, ${ }^{35}$ whereas lysozymes cleave the PG chains between the C-1 of MurNAc and the C- 4 of GlcNAc. ${ }^{36,37,38,39}$ Considering the conservation of the three-dimensional structure of GH18 members from diverse taxa, ${ }^{40}$ one can speculate that GH18 chitinases which are able to hydrolyze PG molecules exhibit a cleavage specificity similar to that reported for hevamine. In summary, the denomination of these bifunctional GH18 enzymes as chitinases/peptidoglycan hydrolases seems to be more appropriate than the term chitinases/lysozymes.

CpCHI, a GH19 papaya chitinase, exhibited antibacterial activity towards E. coli, but the authors did not investigate if the enzyme had lysozyme activity. ${ }^{20}$ Besides GH18 enzymes with hydrolytic activity on PG, bacterial and plant $\mathrm{GH} 19$ chitinases with the same activity have been also found. ${ }^{26,41} \mathrm{GH} 19$ chitinases, chitosanases (E.C. 3.2.1.132; family GH46) and lysozymes (families GH22, GH23 and GH24) share a similar fold, and are classified in the lysozyme superfamily. ${ }^{42}$ Therefore, $\mathrm{CpCHI}$ and other GH19 chitinases probably hydrolyze PG chains, which causes bacterial cell lysis, through the same molecular mechanism as lysozymes. 


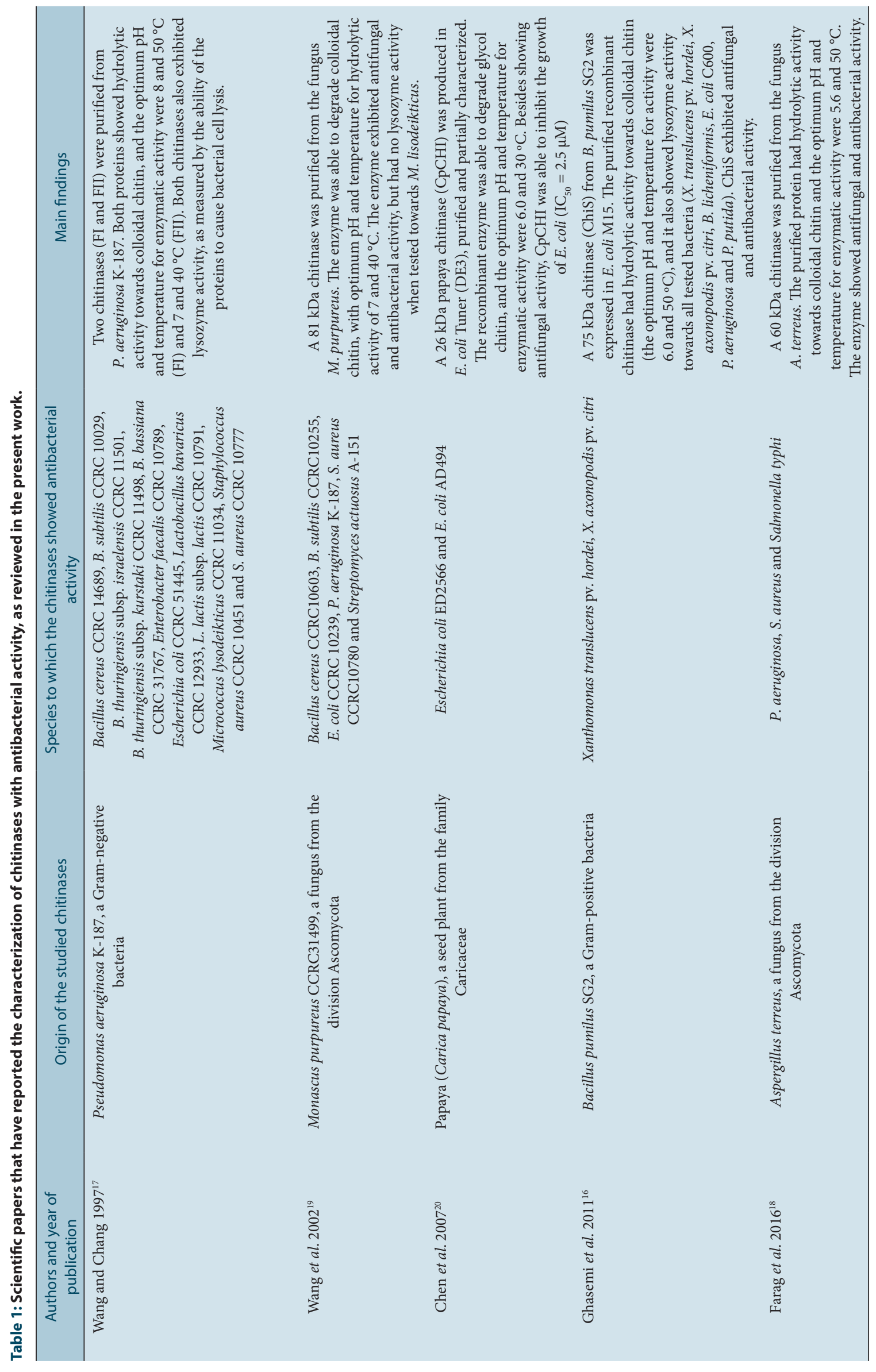


One antibacterial chitinase, purified from the fungus $M$. purpureus, did not show lysozyme activity, when tested towards cell suspensions of M. lysodeikticus. ${ }^{19}$ Fleming was the first scientist to isolate M. lysodeikticus, and due to its high susceptibility to lysozyme, he used this Gram-positive species in his pioneer work, ${ }^{33}$ and the same microorganism has been used until today in lysozyme activity assays. Wang et al. used M. lysodeikticus to determine if the $M$. purpureus chitinase had lysozyme activity, but the antibacterial tests were performed using different Gram-positive and Gram-negative bacteria. Bacteria can evolve efficient mechanisms which protect them from the lytic activity of lysozyme, ${ }^{43}$ including M. lysodeikticus. ${ }^{44,45}$ Therefore, the absence of lysozyme activity of $M$. purpureus chitinase should be carefully interpreted and re-examined, using the same species to which the protein exhibited antibacterial effects. Moreover, large variations in the PG fine structure exist between species, which may occur even within the same species, as a function of medium composition and culture age. ${ }^{31}$ This may explain previous results in which ChiS chitinase showed lysozyme activity towards 6 bacterial species, but only 2 of these species were killed by the same enzyme. ${ }^{16}$

Concerning the potential exploitation of antibacterial chitinases as antimicrobial agents, the GH18 enzymes are particularly interesting, because they are likely to degrade bacterial cell walls using a mechanism that is distinct from that used by lysozymes. This possibility seems very attractive when we consider that some human pathogenic bacteria, such S. aureus and other species, are resistant to lysozyme. ${ }^{46}$

\section{CONCLUSION}

Only a few chitinases have been investigated as potential antibacterial proteins. However, a growing number of publications have reported that many of these chitinolytic enzymes, besides being able to degrade chitin, also have the ability do cleave peptidoglycan chains, thus promoting the lysis of bacterial cells. The peptidoglycan hydrolase activity of chitinases should be investigated in more detail, as their antibacterial activities could be exploited to control pathogenic bacteria.

\section{CONFLICT OF INTEREST}

There is not conflicting interest.

\section{ACKNOWLEDGEMENT}

SCM was recipient of a Doctoral Fellowship from CAPES (Coordenação de Aperfeiçoamento de Pessoal de Nível Superior). TBG is a senior researcher of CNPq (Conselho Nacional de Desenvolvimento Cientifico e Tecnológico).

\section{ABBREVIATIONS}

GlcNAc: $N$-acetyl- $\beta$-D-glucosamine; GHs: glycoside hydrolases; CAZy: Carbohydrate-Active Enzymes; (GlcNAc)2: $N, N^{\prime}$-diacetylchitobiose; (GlcNAc)3: $N, N^{\prime}, N^{\prime \prime}$-triacetylchitotriose; CHS: chitin synthase; PG: peptidoglycan; MurNAc: GlcNAc and N-acetylmuramic acid residues.

\section{REFERENCES}

1. Muzzarelli RAA. Chitin. 1st ed. Oxford: Pergamon Press Ltd. 1977.

2. Tang WJ, Fernandez J, Sohn JJ, Amemiya CT. Chitin is endogenously produced in vertebrates. Curr Biol. 2015;25(7):897-900.

3. Cantarel BL, Coutinho PM, Rancurel C, Bernard T, Lombard V, Henrissat B. The Carbohydrate-Active EnZymes database (CAZy): An expert resource for Glycogenomics. Nucleic Acids Res. 2008;37(1):233-8.

4. Henrissat B. A classification of glycosyl hydrolases based on amino acid sequence similarities. Biochem J. 1991;280(2):309-16.

5. Merzendorfer $\mathrm{H}$. The cellular basis of chitin synthesis in fungi and insects: common principles and differences. Eur J Cell Biol. 2011;90(9):759-69.

6. Gooday GW. The Ecology of Chitin Degradation. Adv. Microb. Ecol. 1990;11:387-430.

7. Van Loon LC, Rep M, Pieterse CMJ. Significance of inducible defense-related proteins in infected plants. Annu Rev Phytopathol. 2006;44:135-62.

8. Selin C, De Kievit TR, Belmonte MF, Fernando WGD. Elucidating the Role of Effectors in Plant-Fungal Interactions: Progress and Challenges. Front Microbiol. 2016;7:600

9. Renner T, Specht CD. Inside the trap: gland morphologies, digestive enzymes, and the evolution of plant carnivory in the Caryophyllales. Curr Opin Plant Biol. 2013;16(4):436-42

10. Seidl V. Chitinases of filamentous fungi: a large group of diverse proteins with multiple physiological functions. Fungal Biology Reviews. 2008;22(1):36-42.

11. Horiuchi A, Aslam M, Kanai T, Atomi H. A Structurally Novel Chitinase from the Chitin-Degrading Hyperthermophilic Archaeon Thermococcus chitonophagus. Appl Environ Microbiol. 2016;82(12):3554-62.

12. Cletus J, Balasubramanian V, Vashisht D, Sakthivel N. Transgenic expression of plant chitinases to enhance disease resistance. Biotechnol Lett. 2013 35(11):1719-32.

13. Yang J, Liang L, Li J, Zhang K-O. Nematicidal enzymes from microorganisms and their applications. Appl Microbiol Biotechnol. 2013;97(16):7081-95.

14. Chen L, Jiang H, Cheng $Q$, Chen J, Wu G, Kumar A, et al. Enhanced nematicidal potential of the chitinase pachi from Pseudomonas aeruginosa in association with Cry21Aa. Sci Rep. 2015;5:14395.

15. Yang $Y, Y u$ B. Recent advances in the synthesis of chitooligosaccharides and congeners. Tetrahedron. 2014;70(5):1023-46.

16. Ghasemi S, Ahmadian G, Sadeghi M, Zeigler DR, Rahimian H, Ghandili S, et al. First report of a bifunctional chitinase/lysozyme produced by Bacillus pumilus SG2. Enzyme Microb Technol. 2011;48(3):225-31.

17. Wang SL, Chang WT. Purification and characterization of two bifunctional chitinases/lysozymes extracellularly produced by Pseudomonas aeruginosa K-187 in a shrimp and crab shell powder medium. Appl Environ Microbiol. 1997;63(2):380-6.

18. Farag AM, Abd-Elnabey HM, Ibrahim HAH, El-Shenawy M. Purification, characterization and antimicrobial activity of chitinase from marine-derived Aspergillus terreus. The Egyptian Journal of Aquatic Research. 2016;42(2):180-6.

19. Wang SL, Hsiao WJ, Chang WT. Purification and characterization of an antimicrobial chitinase extracellularly produced by Monascus purpureus CCRC31499 in a shrimp and crab shell powder medium. J Agric Food Chem. 2002;50(8):2249-55

20. Chen YT, Hsu LH, Huang IP, Tsai TC, Lee GC, Shaw JF. Gene cloning and char acterization of a novel recombinant antifungal chitinase from papaya (Carica papaya). J Agric Food Chem. 2007;55(3):714-22.

21. Wang $S$, Shao $B$, Rao $P$, Lee $Y$, Ye X. Hypotin, a novel antipathogenic and antiproliferative protein from peanuts with a sequence similar to those of chitinase precursors. J Agric Food Chem. 2007;55(24):9792-9.

22. Qin C, Huang W, Zhou S, Wang X, Liu H, Fan M, et al. Characterization of a novel antimicrobial peptide with chitin-biding domain from Mytilus coruscus. Fish Shellfish Immunol. 2014;41(2):362-70.

23. Schlumbaum A, Mauch F, Vögeli U, Boller T. Plant chitinases are potent inhibitors of fungal growth. Nature. 1986;324(6095):365

24. Gonçalves IR, Brouillet S, Soulié M-C, Gribaldo S, Sirven C, Charron N, et al. Genome-wide analyses of chitin synthases identify horizontal gene transfers towards bacteria and allow a robust and unifying classification into fungi. BMC Evol Biol. 2016;16(1):252.

25. Bernasconi P, Locher R, Pilet PE, Jollès J, Jollès P. Purification and N-terminal amino-acid sequence of a basic lysozyme from Parthenocissus quinquifolia cultured in vitro. Biochim. Biophys. Acta - Protein Struct. Mol. Enzymol. 1987 915(2):254-60.

26. Hosoda N, Kurokawa Y, Sako Y, Nagasaki K, Yoshida T, Hiroishi S. The functional effect of Gly209 and lle213 substitutions on lysozyme activity of family 19 chitinase encoded by cyanophage Ma-LMM01. Fish Sci. 2011;77(4):665-70.

27. Patel AK, Singh VK, Yadav RP, Moir AJG, Jagannadham MV. ICChl, a glycosylated chitinase from the latex of Ipomoea carnea. Phytochemistry. 2009;70(10):1210-6

28. Tata SJ, Beintema JJ, Balabaskaran S. Iysozyme of Hevea brasiliensis latex: isolation, purification, enzyme kinetics and a partial amino-acid sequence. J. Rubb. Res. Inst. Malays. 1983;31:35-48.

29. Terwisscha van Scheltinga AC, Hennig M, Dijkstra BW. The 1.8 A resolution structure of hevamine, a plant chitinase/lysozyme, and analysis of the conserved sequence and structure motifs of glycosyl hydrolase family $18 . \mathrm{J} \mathrm{Mol}$ Biol. 1996;262(2):243-57.

30. Egan AJF, Cleverley RM, Peters K, Lewis RJ, VollmerW. Regulation of bacterial cell wall growth. FEBS J. 2017;284(6):851-67.

31. Vollmer W, Blanot D, De Pedro MA. Peptidoglycan structure and architecture FEMS Microbiol Rev. 2008;32(2):149-67.

32. El Zoeiby A El, Sanschagrin F, Levesque RC. Structure and function of the Mur enzymes: development of novel inhibitors. Mol Microbiol. 2003;47(1):1-12.

33. Fleming A, B M, S FRC. On a remarkable bacteriolytic element found in tissues and secretions. Proc R Soc Lond B. 1922;93(653):306-17.

34. Ragland SA, Criss AK. From bacterial killing to immune modulation: Recent insights into the functions of lysozyme. PLoS Pathog. 2017;13(9):e1006512.

35. Bokma E, Van Koningsveld GA, Jeronimus-Stratingh M, Beintema JJ. Hevamine, 
a chitinase from the rubber tree Hevea brasiliensis, cleaves peptidoglycan between the $\mathrm{C}-1$ of $\mathrm{N}$-acetylglucosamine and $\mathrm{C}-4$ of $\mathrm{N}$-acetylmuramic acid and therefore is not a lysozyme. FEBS Letters. 1997;411(2):161-3.

36. Audy P, Trudel J, Asselin A. Purification and characterization of a lysozome from wheat germ. Plant Sci. 1988;58(1):43-50.

37. Howard JB, Glazer AN. Papaya lysozyme. Terminal sequences and enzymatic properties. J Biol Chem. 1969;244(6):1399-409.

38. Strynadka NC, James MN. Lysozyme revisited: crystallographic evidence for distortion of an $\mathrm{N}$-acetylmuramic acid residue bound in site D. J Mol Biol. $1991 ; 220(2): 401-24$.

39. Tsugita A, Inouye M. Purification of bacteriophage T4 lysozyme. J Biol Chem. 1968;243(2):391-7.

40. Funkhouser JD, Aronson NN. Chitinase family GH18: Evolutionary insights from the genomic history of a diverse protein family. BMC Evol Biol. 2007;7(1):96.

41. Suarez V, Staehelin C, Arango R, Holtorf H, Hofsteenge J, Meins F. Substrate specificity and antifungal activity of recombinant tobacco class I chitinases. Plant Mol Biol. 2001;45(5):609-18.

42. Wohlkönig A, Huet J, Looze Y, Wintjens R. Structural relationships in the lysozyme superfamily: significant evidence for glycoside hydrolase signature motifs. PLoS ONE. 2010;5(11):e15388.

43. Kraus D, Peschel A. Staphylococcus aureus evasion of innate antimicrobial defense. Future Microbiol. 2008;3(4):437-51.

44. Brumfitt W, Wardlaw AC, Park JT. Development of Lysozyme-Resistance in Micrococcus Lysodiekticus and its Association with an Increased O-Acetyl Content of the Cell Wall. Nature. 1958;181(4626):1783.

45. Litwack G, Prasad AL. Development of Iysozyme resistance in Micrococcus lysodeikticus and Sarcina lutea. Nature. 1962;196(4854):543-5.

46. Bera A, Biswas R, Herbert S, Götz F. The presence of peptidoglycan O-acetyltransferase in various staphylococcal species correlates with lysozyme resistance and pathogenicity. Infect Immun. 2006;74(8):4598-604.

Article History: Submission Date : 17-01-2018 ; Revised Date : 10-02-2018; Acceptance Date : 17-02-2018.

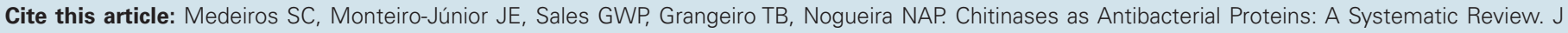
Young Pharm. 2018;10(2):144-8. 